\title{
NON-MENDELIAN FEMALE STERILITY IN DROSOPHILA MELANOGASTER: INFLUENCE OF AGEING AND THERMIC TREATMENTS
}

\section{EVIDENCE FOR A PARTLY INHERITABLE EFFECT OF THESE TWO FACTORS}

\author{
ALAIN BUCHETON \\ Laboratoire de Génétique, Université de Clermont-Ferrand II, B.P. 45, 63170 Aubière, France
}

Received 17.v.78

\begin{abstract}
Summary
Crosses between certain Drosophila melanogaster strains may give rise to female sterility of non-Mendelian determination. Reduced fertility is observed in F1 females, known as $S F$ females, from crosses between females of " reactive" strains and males of "inducer" strains. The extent of this reduction of fertility depends on the strains which are used in the cross and on two nongenetic factors : age and temperature. The fertility of $S F$ females increases with ageing. Also, exposing them for a short period to a high temperature $\left(29^{\circ} \mathrm{C}\right)$ either increases or decreases the probability of hatching of the eggs according to the stage of oogenesis at which the heat treatment is applied. A very striking point is that qualitatively quite similar, though attenuated, effects are observed when the two factors (ageing and temperature) are applied not directly to $S F$ females, but to their maternal ancestors: mothers and grandmothers.
\end{abstract}

\section{INTRODUCTION}

Grosses between various Drosophila melanogaster strains may produce F1 females showing more or less reduced fertility. On the basis of this phenomenon, any strain can be placed in one of three categories: reactive, inducer or neutral. The reduction of fertility is observed in the females, called $S F$ females, produced by crossing females of reactive strains with males of inducer strains. Reciprocal crosses (inducer females $\times$ reactive males) give normally fertile females (called $R S F$ females), as do crosses involving neutral strains or crosses within any one of the three classes of strains (Picard et al., 1972a).

A survey of a large number of strains has shown that all those originating from flies recently caught in the wild are inducer, whereas laboratory strains may be inducer, reactive or neutral. The reactive and neutral states appear therefore to be the outcome of genetic changes which may occur within small isolates maintained in laboratory conditions (Picard et al., 1976). Several authors (Rosenfeld et al., 1971; Sved, 1976; Kearsey et al., 1977; Kidwell et al., 1977) have reported upon sterilities which appear to show analogies with the $S F$ sterility phenomenon.

$S F$ female sterility displays quite specific physiological characteristics. In the eggs which do not hatch, development is blocked before the blastoderm stage and, in those which succeed in passing through this critical stage, the rest of the development appears to be normal. The hatching percentage 
varies with the age and the ambient temperature of the females. It does not depend on the males with which the $S F$ females are crossed, and Mendelian segregations are not noticeably modified within the progenies of these females (Picard et al., 1977).

The sterility of $S F$ females is the result of an interaction between two genetic factors, of as yet unknown nature: the one which is derived from the reactive strains has been called $R$, that from the inducer strains is designated by $I$ (Picard et al., 1972b).

The $I$ factor, when transmitted by males, is strictly linked to inducer strain chromosomes. In contrast, in heterozygous females with chromosomes from both reactive and inducer origin, the chromosomes of reactive origin may acquire the inducer character, independently of the production of recombined gametes. This phenomenon has been called chromosomal contamination (Picard, 1976).

Both factors, $R$ and $I$, show a large quantitative variation, the intensity of the sterility of $S F$ females depending to a large extent upon the choice of their reactive and inducer parents. The level of reactivity of a reactive female can be defined as the extent of fertility reduction of the $S F$ daughters obtained after its cross with standard inducer males. A female is considered as strongly reactive when the hatching percentage of the eggs laid by its $S F$ daughters is low. It is considered as weakly reactive when this hatching percentage is high (Bucheton et al., 1976). Some reactive strains have a mixture of strongly and weakly reactive females, and females of intermediate reactivity. From such strains, selection or spontaneous drift may give rise to strong or weak families which include either only strongly reactive or only weakly reactive females respectively (Picard et al., 1972a; Bucheton, 1973).

Crosses between weakly reactive females and males from a strongly reactive strain give a majority of weakly reactive $\mathrm{Fl}$ females and a minority of intermediate types. The reciprocal crosses (strongly reactive females by males from a weakly reactive strain) give a majority of strongly reactive $\mathrm{F} 1$ females and a minority of intermediate types. The level of reactivity of a female seems therefore mainly determined by maternal heredity, but depends to some extent on the father (Bucheton, 1973). This paternal influence is linked to all three major chromosomes, whose effects appear even when they are heterozygous, and are additive as in a case of quantitative inheritance (Bucheton and Picard, 1978).

The action of chromosomes can accumulate over the course of generations. Reactive families bred in maternal line from a strongly reactive strain but containing chromosomes from a weak strain, evolve progressively towards a state of weak reactivity. This transformation requires at least 10 generations for completion. The reverse change, from weak to strong reactivity has also been observed in a strain bred in maternal line from a weakly reactive strain but containing chromosomes from a strong strain. Reactivity thus appears to be the expression of a cytoplasmic state likely to a large quantitative variation, which tends to be transmitted unchanged from a female to her daughters. However, this state is influenced by a polygenic chromosomal system and, in the long run, it is the chromosomal genotype which determines the level of reactivity (Bucheton and Picard, 1978).

Two factors can considerably modify the sterility of $S F$ females: their 
age and heat treatments. The hatching percentage of eggs increases regularly with age and, in addition, can be reversibly increased by submitting the $S F$ females to heat treatments (Picard, 1971; Picard et al., 1977). From preliminary studies (Bucheton and Picard, 1975), it is known that ageing acts not only on $S F$ females, but also on their reactive mothers, for $S F$ females from older mothers are correspondingly less sterile. This ageing effect is also observed, although to a much smaller extent, with the reactive grandparents of $S F$ females.

In the present paper are reported more precise experiments intended to analyse the mode of action of ageing and heat treatments in reactive and $S F$ females, and to determine how these modifications are transmitted from one generation to the next.

\section{MATERIALS AND METHODS}

The flies are raised on the axenic food described by David (1959).

\section{(i) Strains}

$e_{s t 28}$ is a strongly reactive family, obtained by selection following the method described by Picard et al. (1972a), from a strain homozygous for the mutation ebony.

$B 2^{\prime}$ and $L u$ are two wild type inducer strains bred from flies captured in the wild in 1972, in western France, and in 1969 in southern France respectively.

\section{(ii) Measurement of the hatching percentages of eggs}

The females whose fertility is to be measured were placed in tubes containing axenic food to which carbon black is added. In all the experiments, the measurements concern the overall fertility of groups of 30 to 50 females. Their eggs were collected during 24 hours. Forty-eight hours later, hatched and unhatched eggs were counted and the hatching percentage calculated. The females whose fertility is studied were crossed with their brothers.

\section{(iii) Heat treatments}

The strains are normally maintained at $20^{\circ} \mathrm{C}$. All experiments were made at this same temperature. The thermic treatments were at $29 \pm 0.5^{\circ} \mathrm{C}$, except for the inducer males, for which they were at $27 \cdot 5 \pm 0 \cdot 5^{\circ} \mathrm{C}$.

\section{Results}

Three experiments were carried out simultaneously to study the influences of ageing and heat treatments on $S F$ female sterility. They differed by the generation of flies involved: $S F$ females, their reactive mothers, and their reactive grandparents. In all cases, the reactive strain $e_{s t 28}$ and the inducer strain $B 2^{\prime}$ were used.

\section{(i) Action on $\mathrm{SF}$ females}

Mass crosses between young $e_{s t 28}$ reactive females and $B 2^{\prime}$ inducer males were made, and within the offspring, 20 groups, each containing about 30 
$S F$ females, were constituted. These $S F$ females were mated with their brothers. The flies were transferred every 24 hours to tubes containing fresh medium. The successive layings were kept and their hatching percentages determined.

Ten of the 20 groups (series $\mathrm{C}$ ) were maintained permanently at $20^{\circ} \mathrm{C}$.

The flies of the 10 other groups (series D) were submitted, to a heat treatment from the 5 th to the 9 th day after eclosion. After the 9 th day they were returned at the temperature of $20^{\circ} \mathrm{G}$. Even during the heat treatment eggs were collected every 24 hours, and kept at $20^{\circ} \mathrm{C}$ for 48 hours before the counts of hatching were made.

For each series, and for each of the successive layings, the $S F$ females can be characterised by a value which corresponds to an average of 10 measurements of fertility.

The change of $S F$ female fertility with age was followed with the $\mathrm{C}$ series and the consequences of a heat treatment on adult $S F$ females was studied in the $\mathrm{D}$ series.

$R S F$ females were used as control. For this, mass crosses between inducer $B 2^{\prime}$ females and reactive $e_{s t 28}$ males were made. From these crosses, 20 groups, each of $30 R S F$ females, were constituted. These $R S F$ females were crossed with their brothers. The 20 groups were divided into two series of 10 , called $\mathrm{A}$ and $\mathrm{B}$. The $R S F$ females of the A series were maintained in the same conditions as the $S F$ females of the $\mathrm{C}$ series, and the $R S F$ females of the $\mathrm{B}$ series were submitted to a heat treatment applied in the same way as for the $S F$ females of the D series.

For each series, and for each of the successive layings, the $R S F$ females can be characterised by a value which corresponds to an average of 10 measurements of fertility.

The change in fertility of $R S F$ females with age was followed in the A series, and the consequences of a heat treatment on adult $R S F$ females was studied in the B series.

The results are given in fig. 1. Graph A (fig. 1 (a)), corresponding to the A series, shows that the $R S F$ females have normal fertility, which remains high throughout their lives, hatching percentages of their eggs almost always being from 90 to 95 per cent. Graph B (fig. 1 (a)), corresponding to the $\mathrm{B}$ series, shows that a heat treatment at $29^{\circ} \mathrm{C}$ changes but little the fertility of $R S F$ females. The slight drop observed 5 days after the beginning of the treatment may result from the appearance of a slight sterility in the males used to fertilise the $R S F$ females, since the former are submitted to the same conditions as the latter.

In contrast, graph $\mathrm{C}$ (fig. 1 (b)), corresponding to the $\mathrm{C}$ series, shows that the $S F$ females show a relatively high sterility at the beginning of their lives, with hatching percentages of the eggs lower than 20 per cent. However, the fertility increases rapidly and after 2 weeks becomes identical to that of $R S F$ females. Afterwards, the hatching percentages remain normal for the rest of the lives of the $S F$ females.

Graph D (fig. I (b)), corresponding to the D series, shows that a heat treatment at $29^{\circ} \mathrm{C}$ temporarily increases the fertility of $S F$ females. Three days after the beginning of the treatment the hatching percentages of the eggs laid by the $S F$ females of the $\mathrm{D}$ series are significantly higher than those obtained with flies of the same age in the $\mathrm{C}$ series. This difference persists throughout the heat treatment and hatching percentages are almost normal, 


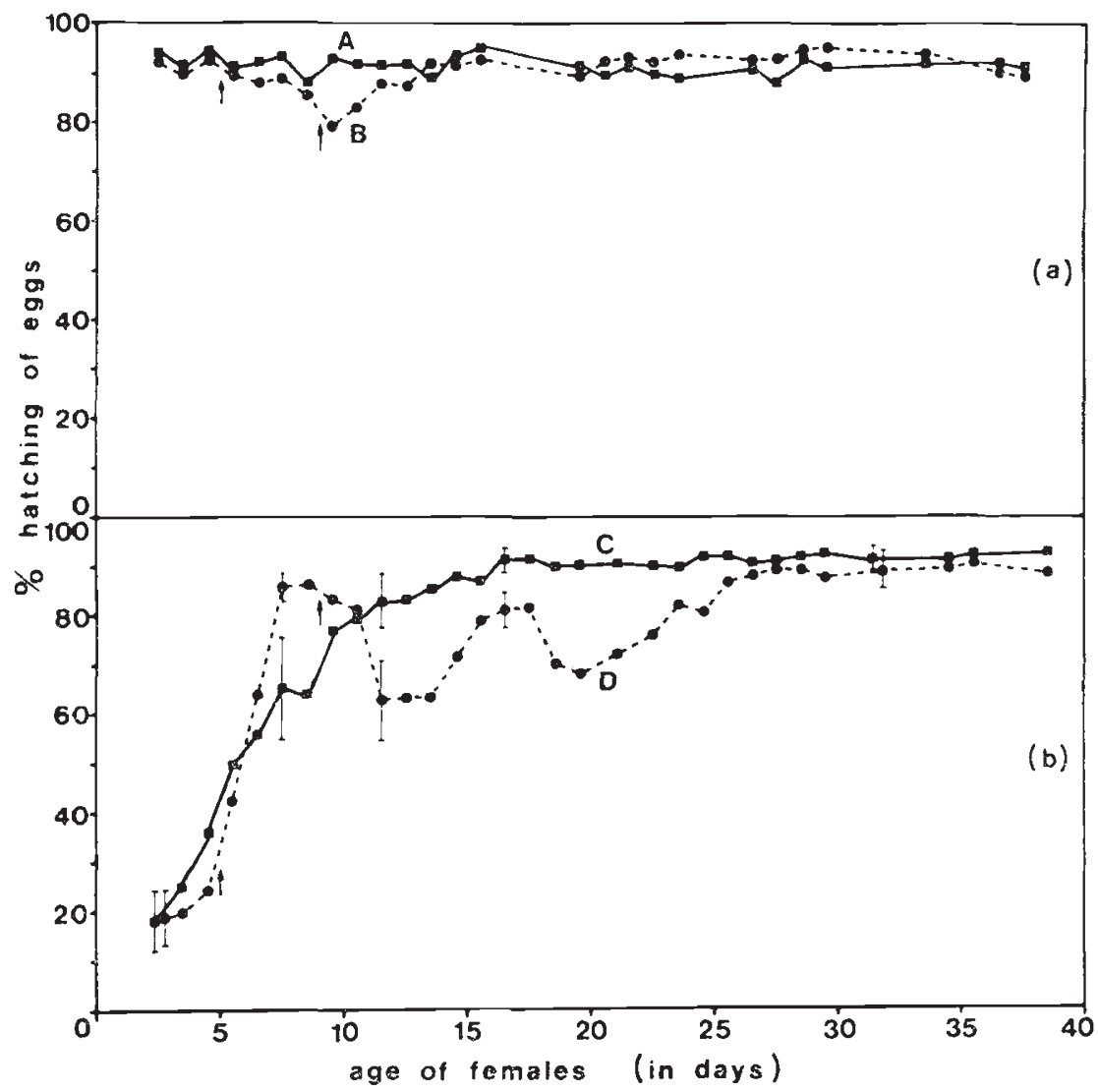

Frg. 1.- Influence of ageing and heat treatment on $R S F$ (a) and $S F$ (b) females. Each point corresponds to the mean of 10 fertility measures. In some cases the confidence intervals are given. The arrows indicate the beginning and end of heat treatments. (a) Squares (graph A) and circles (graph B): actions of ageing and of heat treatment respectively on the fertility of $R S F$ females. (b) Squares (graph C) and circles (graph $\mathrm{D})$ : actions of ageing and heat treatment respectively on the fertility of $S F$ females. The graphs A, B, C, and D correspond to the A, B, C, and D series respectively (see text).

compared with those obtained from the RSF females (fig. I (a)). However, they undergo a drop after the end of the heat treatment, and 3 days later, heated $S F$ females become significantly more sterile than untreated $S F$ females of the same age. Afterwards, the fertility increases progressively with age, but not until the 25 th day does it become comparable with that of the $S F$ females maintained constantly at $20^{\circ} \mathrm{C}$. These results confirm those obtained earlier (Picard, 1971; Picard et al., 1977).

Thus, heat treatments, of adult $S F$ females appear to have two opposite effects. Applied at the end of oogenesis, they cause a decrease in $S F$ female sterility and applied at earlier stages of oogenesis on the contrary, they reinforce sterility. In these experiments, the number of eggs laid by the $S F$ females was not determined, which makes it impossible to define exactly which of the various stages of oogenesis described by King et al. (1956) are heat sensitive. However, data obtained with flies raised at $20^{\circ} \mathrm{C}$ (Bregliano, 
1970) and $25^{\circ} \mathrm{C}$ (King, 1957) suggest that the period during which the heat treatment has a curative effect on sterility is located during vitellogenesis. The other period, corresponding to an increased sterility after heat treatment, would be at earlier stages of oogenesis.

\section{(ii) Action on the reactive mothers of $\mathrm{SF}$ females}

Twenty groups each of five females of the reactive strain $e_{s t 28}$ and five males of the inducer strain $B 2^{\prime}$ were made up. Ten groups (series $\mathrm{E}$ ) were maintained at $20^{\circ} \mathrm{G}$. The flies of the 10 other groups (series F) were submitted to a heat treatment from the 5 th to the 9 th day after eclosion. After the 9 th day they were returned at $20^{\circ} \mathrm{C}$. For the two series, the successive layings of the reactive females were collected every 24 hours and kept afterwards at $20^{\circ} \mathrm{G}$ even during the period when the flies of the $\mathrm{F}$ series were subjected to $29^{\circ} \mathrm{C}$. Every 5 days the inducer $B 2^{\prime}$ males, mates of the $e_{s t 28}$ females, were replaced by younger $B 2^{\prime}$ males.

The $S F$ females bred from the successive layings of the $e_{s t 28}$ females were collected, maintained at $20^{\circ} \mathrm{G}$, crossed in groups with their brothers, and the hatching percentages of their first laid eggs were measured.

Therefore, for each series, and for each successive laying, the prevailing level of reactivity of the $e_{s t 28}$ females was measured as the average of 10 assays of the fertility of their young $S F$ daughters.

The change of level of reactivity of the reactive mothers of $S F$ females with age was followed in the $\mathrm{E}$ series, while in the $\mathrm{F}$ series, the consequences of a heat treatment on these adult reactive females was studied. The results are given in fig. 2 (a).

Graph E, corresponding to the $\mathrm{E}$ series, shows that young $S F$ females are less sterile when they descend from older reactive mothers. The hatching percentages increase from less than 20 per cent for $S F$ females produced by young reactive mothers to more than 60 per cent for $S F$ females produced by reactive mothers aged more than 29 days. This means that the level of reactivity of reactive females diminishes with their age.

The graph F (fig. 2 (a)), corresponding to the F series, shows that the $S F$ female sterility can be reduced by subjecting their reactive mothers to a heat treatment. The $S F$ females which originated from layings between the 4th and 10th day after the beginning of the heat treatment of their reactive mothers are noticeably less sterile (hatching percentages higher than 60 per cent from the 5 th to the 9 th day after the beginning of the heat treatment) than those bred from non-treated reactive females of the same age (hatching percentages around 30 per cent). Later layings give rise to more sterile $S F$ females, and from the 7 th day after the end of the heat treatment onwards the fertility becomes similar to that of flies coming from non-treated reactive mothers of the same age. The application of a heat treatment to adult reactive females thus leads temporarily to less sterile $S F$ daughters. This means that such a treatment induces a reversible change in the level of reactivity of reactive females.

\section{(iii) Possible effect on inducer fathers}

The effects of ageing and heat treatments, when applied to the parents of the $S F$ females, seem to be due essentially to the action of these factors 


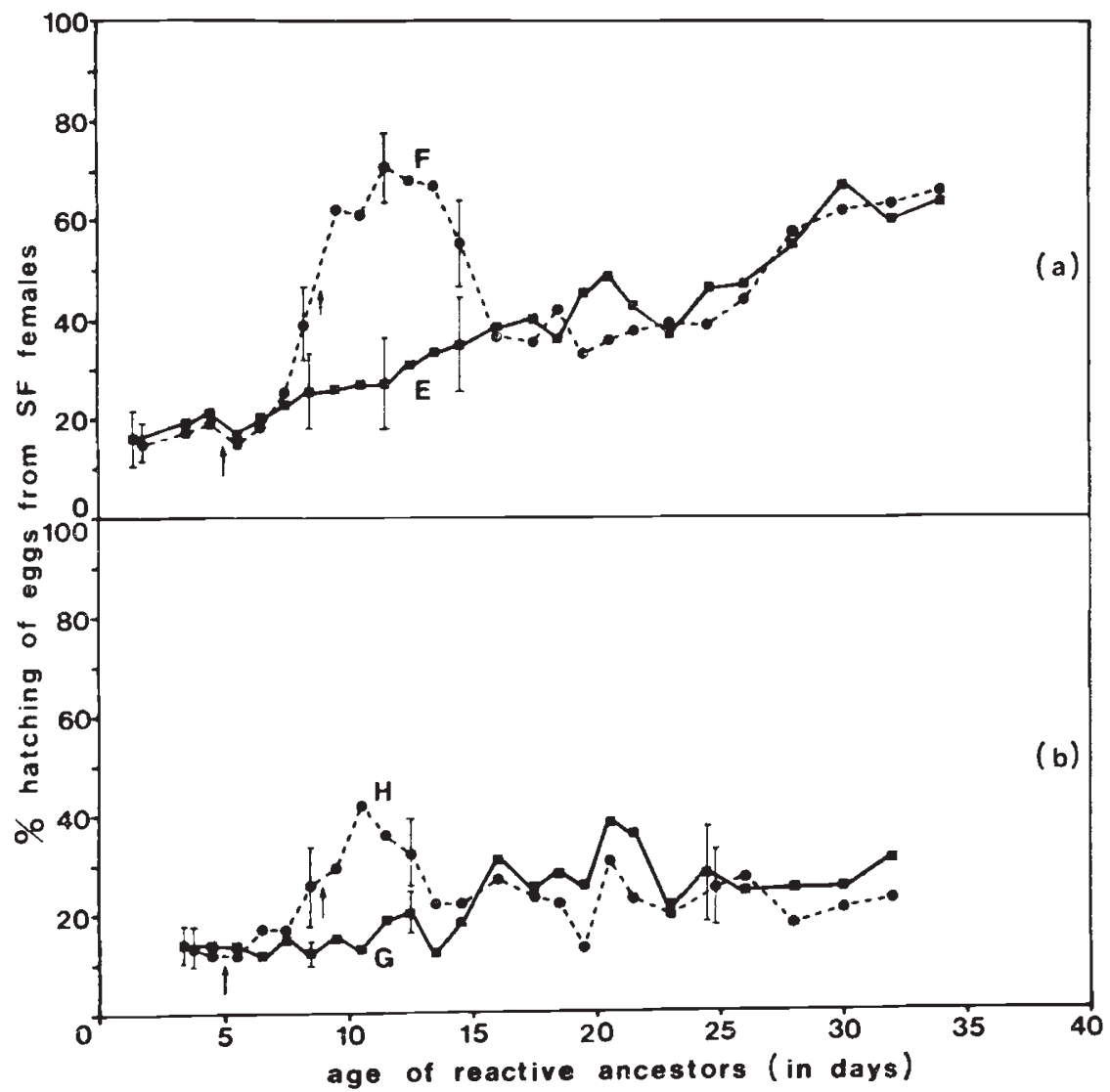

FIG. 2.-Influence of ageing and heat treatments on reactive mothers (a) and grandparents (b) of $S F$ females. Each point corresponds to the mean of 10 measures of fertility of young $S F$ females maintained at a temperature of $20^{\circ} \mathrm{C}$. In some cases the confidence intervals are represented. The abscissa represents age, either of the reactive mothers (a) of $S F$ females, or of the reactive grandparents (b) of $S F$ females. The ordinate represents the hatching percentages of eggs laid by the corresponding young $S F$ females. The arrows indicate the beginning and end of heat treatments of the reactive ancestors of $S F$ females. (a) Squares (graph E) and circles (graph F): actions of ageing and heat treatment respectively on the reactive mothers of $S F$ females. (b) Squares (graph G) and circles $($ graph $\mathrm{H})$ : actions of ageing and heat treatment respectively on the reactive grandparents of $S F$ females. The graphs E, F, G, and $\mathrm{H}$ correspond with the E, F, G, and $\mathrm{H}$ series respectively (see text).

on the reactive mothers. This conclusion is supported by an experiment made to see whether a similar action could be detected on the inducer fathers. Ten groups each of five males of the $L u$ inducer strain were made up. Five groups (series IC) were maintained at $20^{\circ} \mathrm{C}$. The males of the five other groups (series $\mathrm{IH}$ ) were submitted to a heat treatment at $27 \cdot 5^{\circ} \mathrm{C}$ from the 5 th to the 10 th day after eclosion. After the 10th day, they were returned at $20^{\circ} \mathrm{C}$. For the two series, the $L u$ males were crossed periodically with young $e_{s t 28}$ reactive females. The successive $S F$ females from the $L u$ males (always bred from young reactive females raised at $20^{\circ} \mathrm{C}$ ) were collected, maintained at $20^{\circ} \mathrm{C}$, crossed in groups with their brothers, and the hatching percentages, of their first laid eggs were measured. 
Thus, for each series, changes in the inducer efficiency of the $L u$ males could be followed. The inducer efficiency corresponds to the average of five measurements of the $S F$ female sterility. The results are given in fig. 3 . $L u$ being a stronger inducer strain than $B 2^{\prime}$, the hatching percentages of the eggs laid by the $S F$ females are always lower than 10 per cent. The important point is that the measurements corresponding to graph IH are not systematically different from those of graph IC. Therefore, the heat treatment does not modify the inducer efficiency of the males.

In the IC series, the hatching percentages of the eggs from $S F$ females with inducer fathers more than 10 days old are significantly higher than

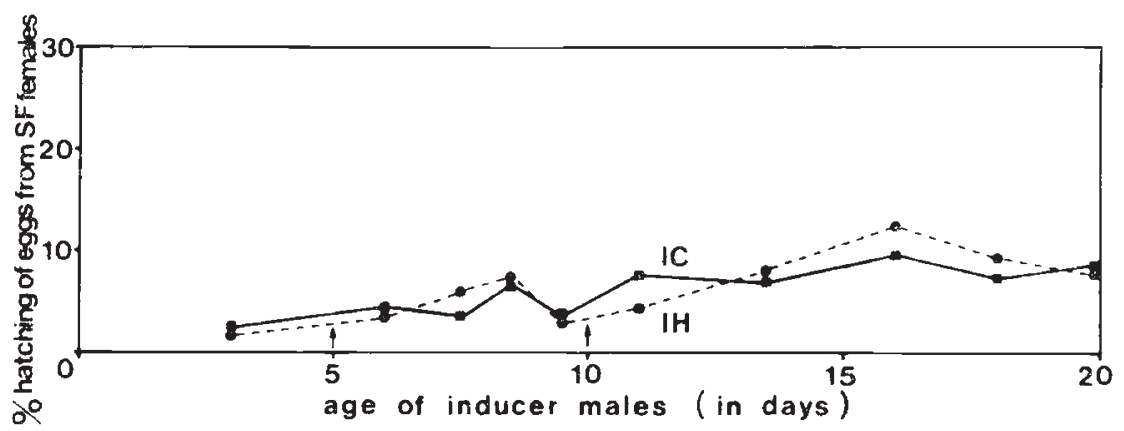

Fig. 3.-Influence of ageing and heat treatment on inducer fathers of $S F$ females. Each point corresponds to the mean of five measures of fertility of young $S F$ females maintained at the temperature of $20^{\circ} \mathrm{C}$. The abscissa represents the age of the inducer fathers, and the ordinate the hatching percentages of the eggs laid by the corresponding young $S F$ females. The arrows indicate the beginning and end of heat treatment of inducer males. Squares (graph IC) and circles (graph IH): actions of ageing and heat treatment respectively on the inducer fathers of $S F$ females. The graphs IC and IH correspond with the IC and IH series respectively (see text).

those from $S F$ females with younger inducer fathers $(t=3.79 ; P<0.001)$. The same is true for the IH series $(t=2.76 ; 0.02<P<0.05)$. This effect need not be attributed to the ageing of the inducer males. It seems more probably due to the successive young reactive females, from which the $S F$ females arose, having been bred from increasingly old reactive mothers. The effects of reactive grandmaternal age are described below.

\section{(iv) Action on the reactive grandparents of $\mathrm{SF}$ females}

Twenty groups each of five females and five males of the reactive $e_{s t 28}$ strain were made. Ten of these groups (G series) were maintained at $20^{\circ} \mathrm{C}$. The flies of the other ten groups (H series) were subjected to a heat treatment from the 5 th to 9 th day after eclosion. They were afterwards returned at $20^{\circ} \mathrm{C}$. For the two series the successive layings of the $e_{s t 28}$ females were collected every 24 hours and maintained at $20^{\circ} \mathrm{C}$, even during the heat treatment period of the flies of the $\mathrm{H}$ series.

From each of the successive layings of each group, five $e_{s t 28}$ reactive females were collected and crossed as a group with five males of the $B 2^{\prime}$ inducer strain, and maintained at a constant $20^{\circ} \mathrm{C}$. The first $S F$ daughters bred from these crosses were collected, crossed in groups with their brothers 
and the hatching percentages for the first laid eggs were determined at $20^{\circ} \mathrm{C}$. For each series, and for each successive laying, the reactive grandparents may then be characterised by a value which corresponds to the average of 10 measurements of the $S F$ female fertility. The transmission from reactive flies to their reactive daughters of the modifications in the level of reactivity induced by ageing is studied with the $G$ series. The $H$ series permits a comparable study concerning the effect of the heat treatment. The results are given in fig. 2 (b).

The graph G, corresponding to the $G$ series, shows that $S F$ females are increasingly less sterile when they descend from increasingly aged reactive grandparents. The hatching percentages of the eggs from the $S F$ females coming from grandparents aged more than 15 days are significantly higher than those obtained with the $S F$ females coming from grandparents aged less than 10 days $(t=7 \cdot 62 ; P<0 \cdot 001)$.

The increase in the hatching percentages of eggs laid by the successive groups of $S F$ females indicates that the level of reactivity of their successive reactive mothers diminishes. This reduction in the level of reactivity of reactive females is, in its turn, a function of the increasing age of their reactive parents. Thus, the reduction in the level of reactivity caused by ageing is inherited.

The graph $\mathrm{H}$ (fig. 2 (b)), corresponding to the $\mathrm{H}$ series, shows that sterility of $S F$ females can be reduced by subjecting their reactive grandparents to a heat treatment. The $S F$ females, descending from eggs laid from the 4th to 8th or 9th day after the beginning of the heat treatment of their reactive grandmothers, are less sterile than those descending from untreated grandmothers of the same age. For the 11 th and 12th days, the mean hatching percengage of the 20 measurements of fertility is $39 \pm 4.5$ per cent in the case of the heated series and $15.8 \pm 1.7$ per cent in the case of the untreated one. The hatching percentages of eggs from $S F$ females of the $\mathrm{H}$ series become reduced for $S F$ females coming from layings of reactive grandparents later than the 2 nd day after the end of the treatment. From the 5th or 6th day after the end of the heat treatment, the $S F$ females obtained show fertility comparable with that of $S F$ females coming from non-treated grandparents of the same age. Thus a heat treatment applied to the reactive grandparents of $S F$ females reduces the sterility of the latter, but the effect is seen only for a few days following the heat treatment.

This transient increase in the hatching percentages of eggs from successive $S F$ females indicates a reduced level of reactivity of their reactive mothers as a result of heat treatment of females of the preceding generation. The modifications in the level of reactivity induced by heat treatment are inherited. Other experiments, the results of which will be published later, indicate that ageing and heat treatments of the reactive grandparents of $S F$ females affect only the females and do not appear to induce any inheritable change in the males.

An interesting point is that ageing, either of $S F$ females or of their maternal ancestors, has qualitatively similar results. However, the effect is much greater when the $S F$ females are aged directly. It is less when the ageing applies to the reactive mothers of $S F$ females and still further reduced when it is the reactive grandparents which are aged. This can be seen in graphs C (fig. l (b)), E, and G (fig. 2 (a) and (b)), which represent the effect of ageing in the three generations. In all cases the hatching percentages are 
similar at the start, from 15 to 20 per cent. However, for flies aged about 30 days, whereas 90 to 95 per cent of the eggs from aged $S F$ females succeed in hatching (graph $\mathrm{C}$ ), only 60 to 65 per cent of those laid by young $S F$ females bred from aged reactive mothers do so (graph E), and the hatching percentages of eggs laid by young $S F$ females originating from aged reactive grandparents reach only 25 per cent (graph G). Thus, the effect of ageing is, although heritable, reduced by passage from one generation to the next.

The same conclusion can be drawn concerning heat treatments of adult flies. The effects of this treatment on the three different generations are qualitatively similar, but become attenuated when applied to increasingly distant ancestors of the $S F$ females. The graphs D (fig. l (b)), F and $\mathrm{H}$ (fig. 2 (a) and (b)) represent the effects of a heat treatment applied respectively to $S F$ females, to their reactive mothers, and to their reactive grandparents. Again, the hatching percentages are similar at the start, from 15 to 20 per cent. But the hatching percentages of eggs laid by $S F$ females reach 85 per cent when these females are heated directly (graph D), 60 or 65 per cent when the heat treatment is applied to their reactive mothers (graph F), and 35 or 40 per cent when it is applied to their reactive grandparents (graph $\mathrm{H}$ ). Therefore, as in the case of ageing, the effect of the heat treatment is inherited but with a gradual attenuation over generations.

It should also be noted that heat treatment of adult $S F$ females has two opposite effects. When applied at the end of oogenesis, it causes an increase in the hatching percentages of their eggs, whereas at an earlier stage it causes a reduction in hatching. The latter effect is not apparent when earlier generations are treated. However, it may exist, but may have been masked in the present data by the attenuating process.

\section{Discussion}

The experimental results reported above show that ageing and temperature influence $S F$ sterility. The hatching percentage of eggs laid by $S F$ females increases with their age, and finally reaches a normal level. Heat treatment of adult $S F$ females causes a temporary increase in the hatching percentage of their eggs, to almost normal levels, but this percentage drops when the treatment is stopped and comes to a level below that of eggs from untreated flies. Heat treatment thus has two opposite effects. When applied at the end of oogenesis, probably during the vitellogenesis stage, it increases the probability of egg hatching, whereas if applied at earlier stages it reduces this probability. Indeed, it is known (Bucheton, 1979), it appears that heat treatments reinforce $S F$ female sterility whatever the stages of larval or pupal development to which they are applied. Thus, late oogenesis appears to be the only period during which they exert a contrary effect.

One of the most interesting aspects of the results is that the modifications induced by ageing and heat treatments are partially heritable. These two factors can modify $S F$ female sterility not only when acting directly on the $S F$ females but also when acting on their maternal ancestors. Thus $S F$ females are less sterile when descended from older reactive mothers. Reactive females submitted to a heat treatment during their imaginal life give less sterile $S F$ daughters, an effect which is reversible. In the same way, less sterile $S F$ females may be obtained by ageing or heat treatment of their reactive 
grandparents. The effect shows a gradual decrease over generations subsequent to ageing or heat treatment.

It was shown earlier (Bucheton and Picard, 1978) that reactivity may be viewed as the expression of a cytoplasmic state, liable to a large quantitative variation, which, in the crosses between strong and weak strains tends to be transmitted without change from a female to its daughters. This cytoplasmic state is influenced by a polygenic chromosomal system, and, in the long run, it is the chromosomal genotype which determines the level of reactivity. The results reported here can be interpreted along the same lines. The gradual reduction in the effects of ageing or heat treatment over generations may be interpreted as the expression of a slow return towards a level of reactivity which is determined by the chromosomal genotype. In addition, the similarity in the effects of ageing and heat treatments on the $S F$ females and on their reactive ancestors suggests that the two factors act in the same way in both cases. Their effects on $S F$ females appear to be the result of their action on the cytoplasmic reactive state.

Sensitivity to ageing or to temperature is observed in many cases of cytoplasmic heredity. For example, cytoplasmic male sterility in Petunia is complete at summer temperatures, whereas fertility is restored at winter temperatures (Izhar and Frankel, 1976). A similar situation is found with Culex pipiens. In this species many cases of cytoplasmic incompatibility have been described and in at least one of these, ageing of the males of one population increases their compatibility with the females of another population (Singh et al., 1976).

In these two cases no heritable effect was shown. But, in some others, heritable changes due to ageing or heat have been described. Thus in yeast; the non-Mendelian genetic elements conferring the killer character are partially or totally lost when the cells are grown at high temperatures (Wickner, 1974). Again in Drosophila melanogaster, the heritability of sternopleural cheata number is influenced by the age of the parents, and it seems that these effects of parental age are persistent (Beardmore et al., 1975). In the same organism, heat treatments, during certain critical phases of development, modify the expression of the mutations eyeless and forked. The induced modifications are maternally transmitted for at least 60 generations (Svetlov and Korsakova, 1972). In the case of cytoplasmic male sterility in Vicia faba, a change of phenotype from sterile to more fertile with age has been observed and these modifications are transmitted to the following generation (Thiellement, 1977a, b). In these last cases the modifications provoked by ageing and heat treatments seem to be stable, and this is a very important difference compared with $S F$ sterility, where the induced modifications become attenuated with the passage of generations.

Unstable modifications caused by environmental factors in various organisms were reviewed by Caspari (1948) and Jinks (1964), and grouped under the term "dauermodifications". In most cases, environmental changes, such as temperature variations, induce phenotypic modifications which tend to be transmitted maternally but disappear progressively in the course of a few generations. Cases of "dauermodifications" have long been known in Drosophila (Jollos, 1934). Indeed, following heat treatments, unstable variations of various characters have been observed. These variations often concern the treated flies themselves and a few immediately following generations, their heredity being entirely maternal. 
The transmission of the extrachromosomal element delta in Drosophila melanogaster is rather similar to the $S F$ sterility phenomenon. Here, temperature affects the rate of multiplication of delta and the mortality of carriers of the element depends on its concentration and on the genotype of the individual. Raising flies at low temperatures reduces the level of delta, but when they are reared again at the usual temperature, the level increases progressively and returns to its original value in about nine generations (Minamori, 1969).

The present observations can be interpreted according to hypotheses advanced earlier (Bucheton, 1973; Bucheton and Picard, 1978). If the genetic elements determining reactivity are extrachromosomal and form an intracellular population, this population might undergo either quantitative or qualitative variations under the influence of both nuclear genes and nongenetic factors. Heat treatments during late oogenesis might act either by favouring the differential multiplication of one type of element, on the hypothesis of a heterogeneous population of extrachromosomal elements, or by modifying the quantity of such elements in the case of a homogeneous population. Ageing might induce a progressive loss of extrachromosomal elements in the course of mitoses.

However, it must be noted that other quite different hypotheses, which do not require the intervention of any non-chromosomal autoreproducible element, can be imagined. The level of reactivity may be the direct expression of the prevailing concentration in the cell of the products of certain genes whose activities are sensitive to environmental and physiological factors. A special explanation would then be required for the very striking inertia with which the level of reactivity responds to a change either in the genotype or in the non-genetic conditions.

Acknowledgements.--I am very grateful to Prof. J. C. Bregliano and Prof. Ph. L'Héritier for advice throughout this work and for helpful comments on the manuscript. This work was supported by grants from the Centre National de la Recherche Scientifique (ERA 692: Phénomènes d'hérédité non mendélienne chez la Drosophile), from the University of Glermont-Ferrand II, and from the Fondation pour la Recherche Médicale Francaise.

\section{REFERENCES}

BEARdMore, J. A., LiNTs, F., AND AL-BALDAwi, A. L. F. 1975. Parental age and heritability of sternopleural chaeta number in Drosophila melanogaster. Heredity, 34, 71-82.

bregliano, J. c. 1970. Etude de l'infection de la lignée germinale chez les Drosophiles femelles infectées avec le virus sigma. II. Mise en évidence d'une correspondance entre les cystes ovariens à rendement viral élevé et les descendants stabilisés. Ann. Inst. Pasteur, 119, 685-704.

Bucheton, A. 1973. Contribution à l'étude de la stérilité femelle non mendélienne chez Drosophila melanogaster. Transmission héréditaire des degrés d'efficacité du facteur " réacteur". Comptes Rend. Acad. Sci., Paris, D, 276, 641-644.

Bucheton, A. 1979. Non-mendelian female sterility in Drosophila melanogaster: influence of ageing and thermic treatments. II. Action of thermic treatments on the sterility of $S F$ females and on the reactivity of reactive females. Biologie Cellulaire, 34, (in press).

BUCHETON, A., LAVIGE, J. M., PICARD, G., AND L'HÉRITIER, PH. 1976. Non-Mendelian female sterility in Drosophila melanogaster: quantitative variations in the efficiency of inducer and reactive strains. Heredity, 36, 305-314.

BUCHETON, A., AND PICARD, G. 1975. Mise en évidence d'une influence partiellement héritable de l'âge sur un phénomène de stérilité femelle à déterminisme non mendélien chez Drosophila melanogaster. Compt. Rend. Acad. Sci., Paris, D, 281, 1035-1038.

BUcheton, A., AND picard, G. 1978. Non-Mendelian female sterility in Drosophila melanogaster: hereditary transmission of reactivity levels. Heredity, 40, 207-223. 
CASPARI, E. 1948. Cytoplasmic inheritance. Adv. Genetics, 2, I-66.

DAvid, J. 1959. Etude quantitative du développement de la Drosophile élevée en milieu axénique. Bul. Soc. Biol. France et Belgique, 93, 4, 472.

IZHAR, S., AND FRANKel, R. 1976. Cytoplasmic male sterility in Petunia. I. Comparative study of different plasmatype sources. 7. Heredity, 67, 43-46.

JINks, J. L. 1964. Extrachromosomal Inheritance. Prentice-Hall, Englewood Gliffs, New Jersey. Jollos, v. 1934. Inherited changes produced by heat-treatment in Drosophila melanogaster. Genetics, 16, 476-494.

KeARSey, M. J., Williams, W. R., Allen, P., AND coulter, F. 1977. Polymorphism for chromosomes capable of inducing female sterility in Drosophila. Heredity, 38, 109-115.

KIDWELL, M. G., KIDWELL, J. F., AND SVED, J. A. 1977. Hybrid dysgenesis in Drosophila melanogaster: a syndrome of aberrant traits including mutation, sterility and male recombination. Genetics, $86,813-833$.

KING, R. C. 1957. Oogenesis in adult Drosophila melanogaster. II. Stage distribution as a function of age. Growth, 21, 95-102.

KING, R. C., RUBINSON, A. C., AND SMITH, R. F. 1956. Oogenesis in adult Drosophila melanogaster. Growth, 20, 121-157.

MINAMORI, s. 1969. Extrachromosomal element delta in Drosophila melanogaster. I. Gene dependence of killing action and of multiplication. Genetics, 62, 583-596.

PICARD, G. 1971. Un cas de stérilité femelle chez Drosophila melanogaster, lié à un agent transmis maternellement. Comptes Rend. Acad. Sci., Paris, D, 272, 2484-2487.

PICARD, G. 1976. Non-mendelian female sterility in Drosophila melanogaster: hereditary transmission of $I$ factor. Genetics, 83, 107-123.

PICARD, G., BUCheton, A., LAVIGe, J. M., AND FLEURIET, A. 1972a. Contribution à l'étude d'un phénomène de stérilité à déterminisme non mendélien chez Drosophila melanogaster. Comptes Rend. Acad. Sci., Paris, D, 275, 933-936.

PICARD, G., BUChETON, A., LAVIGE, J. M., FLEURIET, A., BREgliANo, J. C., AND L'HÉRITIER, PH. 1972b. Further data on non-mendelian female sterility in D. melanogaster. Dros. Inf. Serv., 49, 45.

PICARD, G., BUChETON, A., LAVIGE, J. M., AND PELISSON, A. 1976. Répartition géographique des trois types de souches impliquées dans un phénomène de stérilité à déterminisme non mendélien chez Drosophila melanogaster. Comptes Rend. Acad. Sci., Paris, D, 282, 1813-1816.

Picard, G., LAVIGe, J. M., Bucheton, A., AND bregliano, J. c. 1977. Non-mendelian female sterility in Drosophila melanogaster: physiological pattern of embryo lethality. Biologie Cellulaire, 29, 89-98.

ROSENFELD, A., CARPENTER, A., AND SANDLER, L. 1971. A nonchromosomal factor causing female sterility in D. melanogaster. Dros. Inf. Serv., 47, 85.

SINGH, K. R. P., CURTIS, C. F., AND KRIshNamURThy, B. s. 1976. Partial loss of cytoplasmic incompatibility with age in males of Culex fatigans. Ann. Tropical Med. Parasit., 70, 463-466.

SVED, J. A. 1976. Hybrid dysgenesis in Drosophila melanogaster: a possible explanation in terms of spatial organization of chromosomes. Aust. 7. Biol. Sci., 29, 375-388.

SVETLOV, P. G., AND KORSAKOVA, G. F. 1972. Inheritance of changes in expressivity of eyeless Drosophila melanogaster mutation caused by temperature effects in critical periods of ontogenesis. Sov. 7. Dev. Biol., 2, 279-285.

Thiellement, H. 1977a. La stérilité mâle cytoplasmique chez Vicia faba L. II. Hétérogénéité phénotypique d'une lignée mâle-stérile. Ann. Amélior. Plantes, 27, 547-553.

Thiellement, H. 1977b. La stérilité mâle cytoplasmique chez Vicia faba L. III. Hérédité des phénotypes polliniques. Ann. Amélior. Plantes, 27, 555-562.

WICKNER, R. B. 1974. "Killer character" of Saccharomyces cerevisiae: curing by growth at elevated temperature. 7. Bacteriology, 117, 1356-1357. 